\title{
Sulfonates and Organotrophic Sulfite Metabolism
}

\author{
Alasdair M. Cook, Theo H.M. Smits, Karin Denger
}

\begin{abstract}
One is used to considering sulfite oxidation as part of a lithotrophic process (e.g. SorAB or Sox system), much of which involves neutral or ionic inorganic sulfur species on the outer surface of the cytoplasmic membrane. In contrast, the processes referred to in this chapter involve organic compounds, which (1) include a highly stable sulfonate substituent $\left(\mathrm{C}-\mathrm{SO}_{3}^{-}\right),(2)$ are involved in the organotrophic growth of the organism and (3) much of whose metabolism takes place in the cytoplasm. Many phenomena are associated with this life-style. The sulfonate may be a natural product, e.g. taurine or sulfoquinovose, whose synthesis can involve sulfite, or a xenobiotic laundry detergent, but it is effectively always a charged species, so an uptake system is essential. Two known systems are mentioned, ATP binding cassette transporters and tripartite ATPindependent periplasmic transporters. Annual dissimilation of megatonnes of organosulfonates essentially always involves intracellular sulfite generated by diverse enzymic cleavages in bacteria, archaea and possibly eukarya. The fate of this sulfite in anaerobes is often sulfide. Aerobes occasionally excrete sulfite directly; more frequently, the sulfite is oxidized to sulfate. Many aerobic bacteria excrete only sulfate, but many others excrete also some sulfite, which is rapidly oxidized to sulfate, even under anoxic conditions. The nature and location of these sulfite dehydrogenases are still unclear, but periplasmic SorAB is apparently used by some bacteria. In contrast to the cytochrome $c$ coupled SorAB, there is at least one widespread, uncharacterized sulfite dehydrogenase, which is assayed with ferricyanide as the electron acceptor. Dissimilation of a sulfonate releases sulfite (sulfate) in about 500-fold excess of the sulfur requirement for growth, so exporters, two classes of which have been detected, are essential to prevent the cell from suffering osmotic stress.
\end{abstract}

\subsection{Introduction}

The sulfur cycle has many facets of different magnitudes, and this conference (ISMSM) examined processes involving the major lithotrophic mass fluxes and placed emphasis on membrane-associated processes. Here, the focus is moved to organotrophy with biosynthesis, biotransformation and dissimilation of a group of 


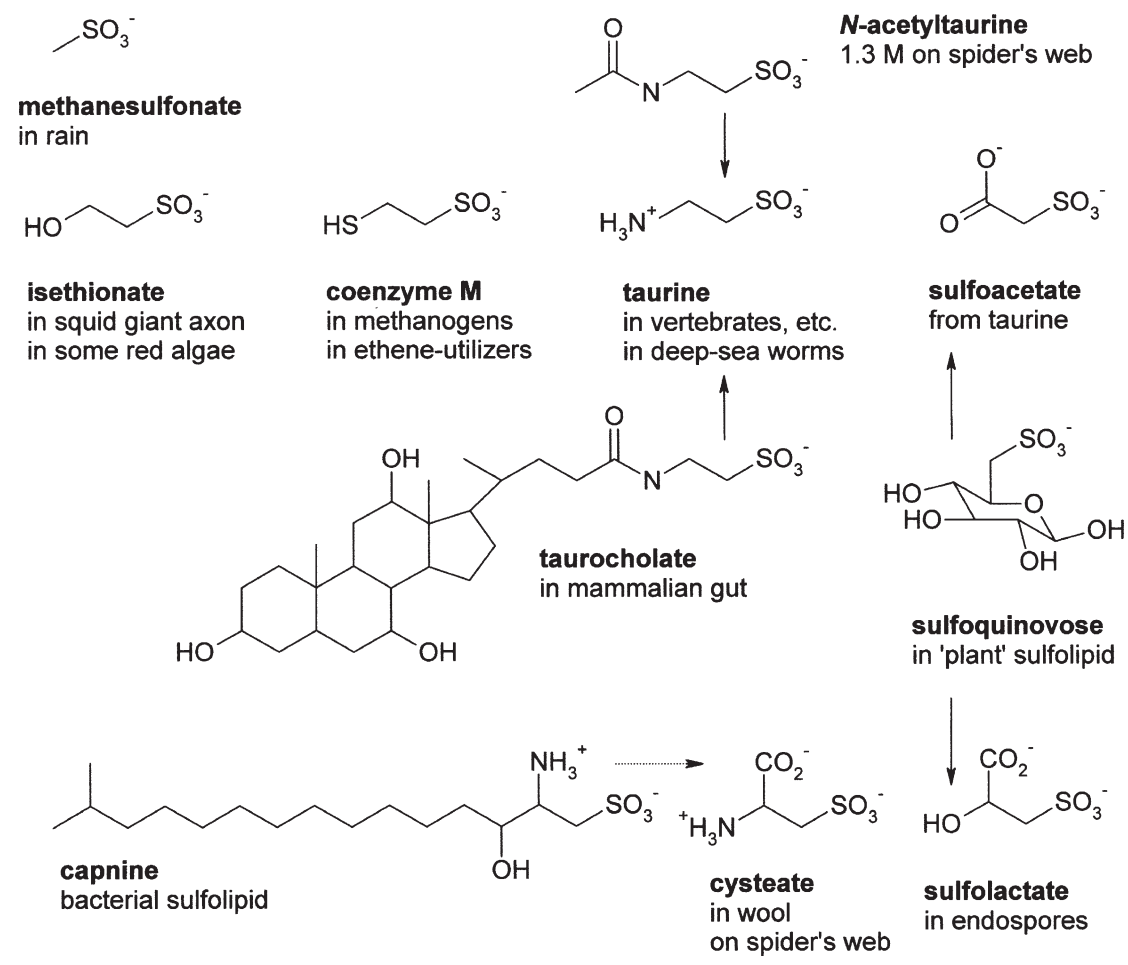

Fig. 14.1 Representative aliphatic organosulfonates from the atmosphere, vertebrates, spiders, bacteria, archaea, plants and algae. The arrows indicate some degradative routes in the literature (Cook and Denger 2002; Cook et al. 2006). Natural sulfonates are obviously ubiquitous, and the $\mathrm{C}_{-} \mathrm{SO}_{3}{ }^{-}$bond is not degraded by, e.g., mammals, which excrete organosulfonates (Huxtable 1992). The widespread utilization of organosulfonates is by microbes, whereby up till now largely bacteria were meant (Cook and Denger 2002; Cook et al. 1999, 2006): utilization by archaea, suggested by sequence data (Rein et al. 2005), has been supported by the first experimental data (J. van der Oost and T.H.M Smits, unpublished data), and utilization by a dinoflagellate is suspected (Mayer et al. 2006)

organic compounds, namely organosulfonates, which contain sulfur in oxidation state +5 (Vairavamurthy et al. 1994; see also Chap. 20 by Prange). These are ancient compounds, some of which have only recently been discovered, e.g. methanesulfonate (Fig. 14.1) with its significance in the sulfur cycle (Baker et al. 1991). Another sulfonate, discovered before organic chemistry became a synthetic science, is taurine, 2-aminoethanesulfonate (Fig. 14.1): it was initially called 'Gallen-Asparagin' (Tiedemann and Gmelin 1827), and the name 'Taurin' was attributed to Gmelin (Demarçay 1838). A century later, den Dooren de Jong (1926) included taurine in some of his studies on microbial nutrition. Many natural organosulfonates of increasing complexity, and sometimes at enormous concentrations, are cited in reviews (Huxtable 1992; Jacobson and Smith 1968; Yancey et al. 2002) 
<smiles>O=C(NCCCNCCCCNC(=O)C1(O)CC1(C(=O)O)C(=O)NCCCCNCCCNC(=O)c1ccc(O)c(O)c1S(=O)(=O)O)c1ccc(O)c(O)c1</smiles>

petrobactinsulfonate bacterial siderophore<smiles>CCCCCC(CC)c1ccc(S(=O)(=O)[O-])cc1</smiles><smiles>O=C(O)CC1(S(=O)(=O)O)C=CC(=O)O1</smiles>

\section{orthanilate} representative for dyestuffs

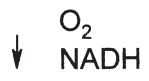<smiles>O=C(O)/C=C/C=C(/O)C(=O)O</smiles><smiles>Cc1ccc(S(=O)(=O)[O-])cc1</smiles><smiles>O=[W](O)(O)O[Na]</smiles><smiles>Cc1ccc(O)c(O)c1</smiles>

\section{4-toluenesulfonate} typical additive, e.g. in pharmaceuticals

Fig. 14.2 A natural arylsulfonate and three commercially available arylsulfonates. The natural product (Hickford et al. 2004) is juxtaposed with one known desulfonation (during ring cleavage) (Junker et al. 1994a): a typical desulfonation prior to ring cleavage (Junker et al. 1994b) and desulfonation subsequent to ring cleavage (Feigel and Knackmuss 1993; Schleheck et al. 2004) are illustrated

and research papers (Abraham et al. 2004; Suzuki et al. 2002; Vollrath et al. 1990) (Fig. 14.1), which lead us to conclude that large quantities of natural sulfonates are being cycled in the food webs in marine and terrestrial environments. Natural aliphatic sulfonates are widely known, but natural arylsulfonates are also being found (Budzikiewicz et al. 1998; Hickford et al. 2004; Ovenden and Capon 1999), one of which is shown in Fig. 14.2.

The degradation of these natural arylsulfonates is presumably the background to the degradation of anthropogenic arylsulfonates. Mankind now uses megatonnes of 
sulfonated surfactants annually, especially linear alkylbenzenesulfonate (Knepper and Berna 2003; Fig. 14.2). Dyestuffs often contain sulfonated moieties (Fig. 14.2). It is normal to formulate cationic pharmaceuticals with sulfonates, both aromatic and aliphatic (O'Neil 2001): recently, a major aid in assisting patients to abstain from alcohol, and that is about $4 \%$ of the population, is a sulfonate, which is dosed at $2 \mathrm{~g} \mathrm{day}^{-1}$ (Cook et al. 2006). Candidate drugs (sulfonates) for stroke and Alzheimer's disease are also dosed at high levels (Cook et al. 2006).

Kondo's group made the first attempts to elucidate degradative pathways for taurine and isethionate (Kondo and Ishimoto 1972), with the consequence that sulfite was recognized as a degradative intermediate. About the same time, biodegradable sulfonated surfactants were introduced in commerce, and Cain recognized that the degradation of model arylsulfonates involved sulfite as an intermediate (Johnston et al. 1975): it now appears that all enzymic desulfonation reactions studied involve the release of sulfite (Cook and Denger 2002; Cook et al. 1999, 2006; Lie et al. 1998). Biosynthesis of natural sulfonates can also involve sulfite (see later). The amounts of sulfite in these organotrophic processes do not compete with those in lithotrophic metabolism, but these several megatonnes of sulfite, the biodiversity in the metabolic pathways and the physiological problems generated (and solved) in these pathways are the backgrounds to this review.

\subsection{Biosynthesis of Organosulfonates}

A major part of our understanding of the biosynthesis of non-carbohydrate, aliphatic sulfonates comes from White $(1984,1986)$, who set out to characterize the biosynthesis of coenzyme $\mathrm{M}$ in methanogenic archaea, and of a sulfolipid in bacteria (capnine; Fig. 14.1). The two turned out to be related (Fig. 14.3), and the later discovery that coenzyme $\mathrm{M}$ is involved in the cleavage of epoxides in aerobic bacteria involved in alkene degradation (Coleman and Spain 2003) broadens the relevance of White's central pathway. White's pathway is involved not only in the generation of sulfolactate for bacterial endospore formation, and L-cysteate for capnine-like lipids (Graham et al. 2002), but, presumably, also for taurine and taurolipids (Fig. 14.3). The key to the sulfonation reaction is a Michael addition of sulfite to the double bond of phosphoenolpyruvate by phosphosulfolactate synthase (EC 4.4.1.19; ComA) (Fig. 14.3).

The synthesis of sulfoquinovose (Fig. 14.1) is also an addition of sulfite to an activated compound, in this case UDP-glucose (Sanda et al. 2001). Half the sulfur in plants is apparently present as sulfoquinovose, and the corresponding sulfolipid is found in photosynthetic algae, protists and bacteria, so this reaction also consumes considerable amounts of sulfite in the biosphere.

The mammalian synthesis of taurine involves an oxygenation of cysteine to cysteine sulfinate, a decarboxylation and an unknown oxidation to taurine (Stipanuk 2004; Fig. 14.4). The important fact here is that the taurine is excreted. Mammals cannot cleave the $\mathrm{C}_{-} \mathrm{SO}_{3}{ }^{-}$bond (Huxtable 1992). Dietary cysteate is apparently excreted as sulfolactate and sulfopyruvate (Weinstein and Griffith 1988). 


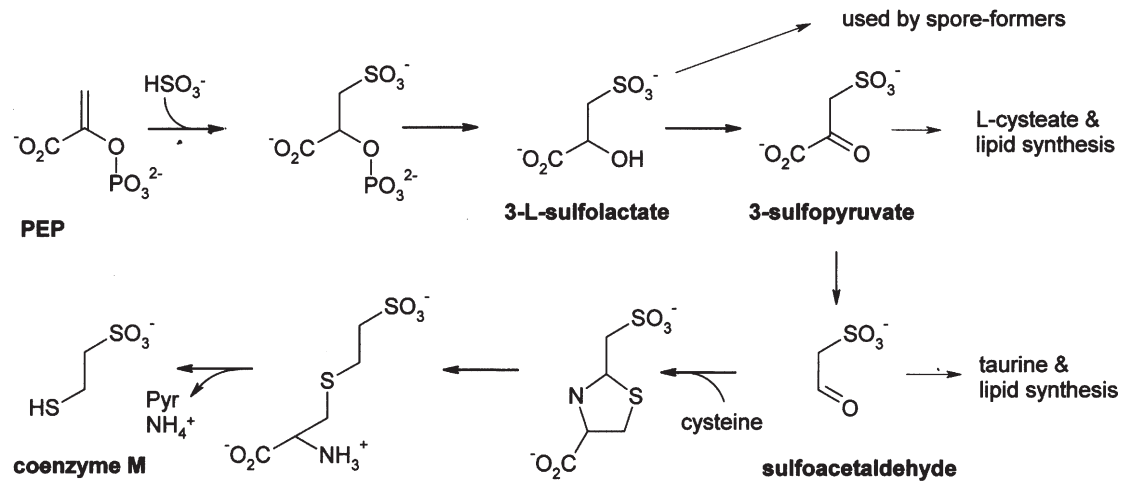

Fig. 14.3 The biosynthesis of coenzyme $\mathrm{M}$ in methanogens (bold arrows) and our interpretation (normal arrows) of the generalized pathway to supply different microorganisms with sulfolactate (spore-formers), L-cysteate for sulfolipids (Cytophagales), taurine for sulfolipids (marine bacteria and some algae) and coenzyme $\mathrm{M}$ for the aerobes which also use the cofactor in biodegradation
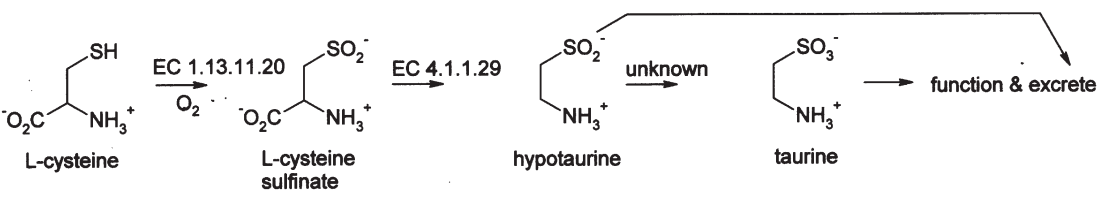

Mammals $\quad$ no biological reaction
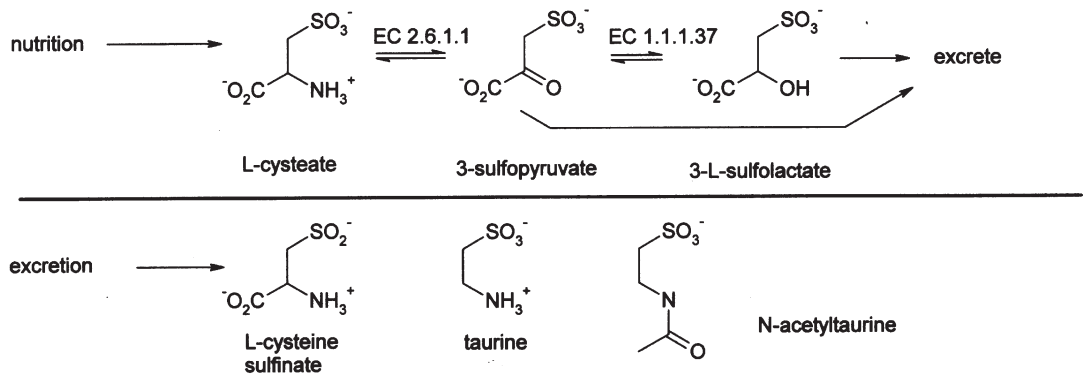

Orb spider's web

weathering?<smiles>[NH3+]C(=O)C[13C](=O)[O-]</smiles>

L-cysteate

Fig. 14.4 Synthesis of taurine in mammals and spiders, and excretion of sulfonates. Taurine has many functions in mammals (Huxtable 1992), but after being functional, the compound is excreted, largely in urine. L-Cysteate in mammals is dietary, and transamination and excretion are indicated (Weinstein and Griffith 1988). Large amounts of sulfonates are involved in the function of spiders' webs (Vollrath et al. 1990) 
Another major source of extracellular sulfonates is spiders' webs (Vollrath et al. 1990; Fig. 14.4). So not only do many organisms produce sulfonates (Fig. 14.3), which will be released when herbivores graze, but many organisms excrete sulfonates (Fig. 14.4) directly into the environment, where biotransformation or dissimilation can take place.

Recent research (Dominy et al. 2006) shows that the oxygenation reaction (EC 1.13.11.20) found in mammals is also present in some bacteria. Apparently this can function as a second pathway to supply sulfolactate for spore formation.

\subsection{Dissimilation of Organosulfonates}

We have seen that the sulfonates are costly to generate. Either a cell invests a high-energy bond to obtain a sulfonate, or it risks oxidative stress by involving an oxygenase. The carbon-sulfonate bond is a strong bond, about as strong as a carbon-carbon bond, and the first organic chemists were astonished at the resistance of taurine to strong acid or alkali. The consequence for the biodegradation of organosufonates is that a very stable bond must be broken. We believe that the natural organosulfonates are phylogenetically ancient entities (Huxtable 1992; Kelly and Murrell 1999), and that the biodiversity we see in desulfonation mechanisms reflects the long exposure of microbes to organosulfonates.

The diversity seen in the desulfonation of arylsulfonates will serve as an introduction. Note that we are talking about dissimilation: M. Kertesz, T. Tralau and A. Schmalenberger (personal communication) introduced a different set of desulfonative enzymes involved in the assimilation of sulfonate sulfur. Some arylsulfonates are desulfonated concomitantly with activation of the ring by multicomponent dioxygenases, as for 4-toluenesulfonate (Fig. 14.2). One case is known in which desulfonation is concomitant with the simpler dioxygenation involved in ring cleavage (Fig. 14.2). And in the third example, (di)oxygenations generate the molecule which can be subtly manipulated and desulfonated by hydrolysis, as in the case of linear alkylbenzenesulfonate (Fig. 14.2). In each case, sulfite is the stoichiometric product of the enzyme reaction.

When we consider the aliphatic sulfonates (Fig. 14.5), we again see sulfite as the stoichiometric product of desulfonation. Methylsulfonate monooxygenase is another multicomponent oxygenase (Kelly and Murrell 1999), and we presume it to be archetypal for many similar reactions (Cook et al. 2006). Suitably placed substituents on sulfonates allow less spectacular desulfonations, as can be seen for sulfolactate and L-cysteate (Fig. 14.5) (Cook et al. 2006). The reaction we know best, inasmuch as we have sketches of complete pathways (see later), is sulfoacetaldehyde acetyltransferase (Xsc) (Fig. 14.5). As in all the desulfonation reactions in Fig. 14.2, the enzymes are soluble and in the cytoplasm.

Now that desulfonations have been introduced, it is relevant to draw attention to, e.g., L-cysteate sulfo-lyase (Fig. 14.5) in a different manner. The substrate carries three charged moieties, and the three products carry one each. None of these 

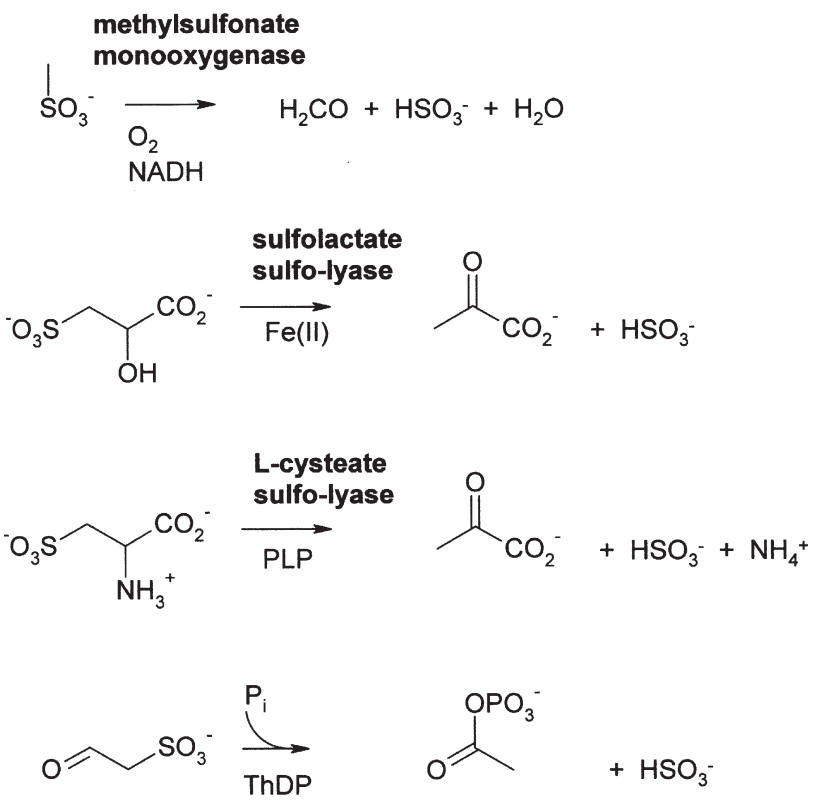

sulfoacetaldehyde acetyltransferase (Xsc)

Fig. 14.5 Some desulfonation reactions. Methanesulfonate monooxygenase is a multicomponent system (MsmABCD), which generates formaldehyde and sulfite from the substrate. Sulfolactate sulfo-lyase has two subunits (SuyAB) and tightly bound Fe(II). L-Cysteate sulfo-lyase (CuyA) represents a third desulfonation mechanism with cofactor pyridoxal 5 -phosphate $(P L P)$. The sulfoacetaldehyde acetyltransferase $(\mathrm{Xsc})$ reaction involves thiamin diphosphate $(T h D P)$ as a cofactor

compounds will pass through a protein-free bimolecular lipid leaflet. The cell needs to keep its carbon source in the cell for energy conservation and growth, so the pyruvate disappears. This potentially leaves the cell with problems, because the nitrogen supply is in about fourfold excess and the sulfur supply is in about 500-fold excess. Not only that, this sulfur source, sulfite, is considered to be toxic. Exploding may be one answer to toxin at high osmotic pressure, but it seems a bit extreme, and considering the amount of desulfonation in extant microorganisms (Figs. 14.2, 14.5), it is obviously not the response that cells have developed.

\subsection{The Detoxification or Fate of Sulfite}

We would like to introduce the critical situation gradually, with the desulfonation reaction that we know from pathways whose genes are found in many genomes (Brüggemann et al. 2004; Cook and Denger 2002, 2006; Cook et al. 2006; Denger et al. 2006a; Gorzynska et al. 2006; Rein et al. 2005). Our hypothesis for the dissimilation of taurine in anaerobic Desulfotalea psychrophila is given in Fig. 14.6. 


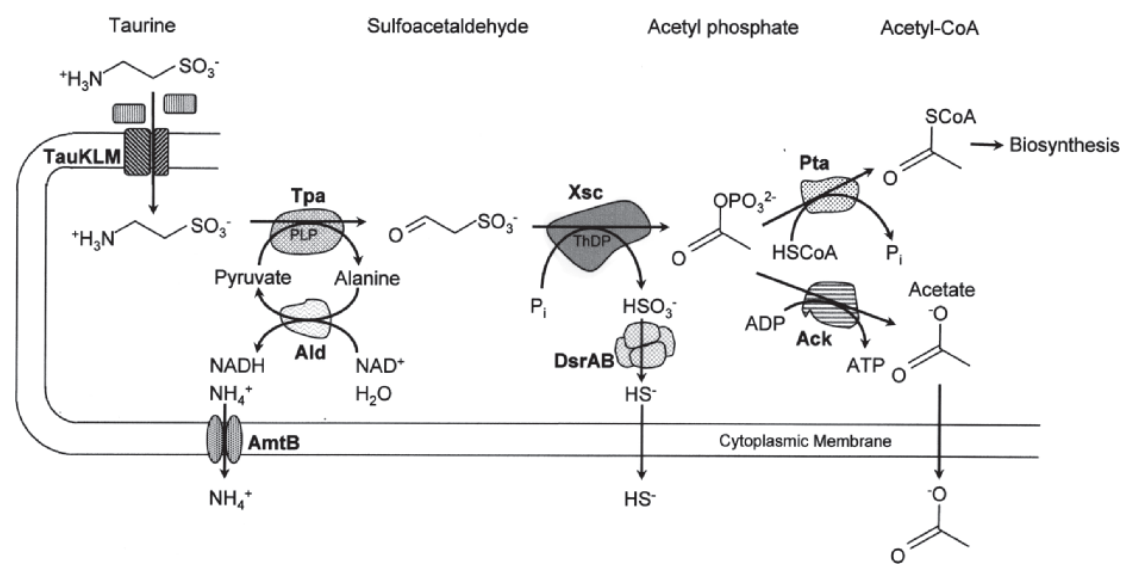

Fig. 14.6 Hypothetical pathway of taurine degradation in Desulfotalea psychrophila LSv54. Given that the organism grows with taurine (R. Rabus, unpublished data), we deduced the pathway from the genome sequence (Rabus et al. 2004) and our experience with related pathways in other organisms (Denger et al. 2006a; Gorzynska et al. 2006). Ack acetate kinase, Ald alanine dehydrogenase, Tpa taurine:pyruvate aminotransferase, DsrAB dissimilatory sulfite reductase, Pta phosphotransacetylase

Gene candidates for a tripartite ATP-independent periplasmic transporter, TauKLM, are present, as are genes to encode a taurine:pyruvate aminotransferase and for the oxidative release by alanine dehydrogenase of the ammonium ion, which presumably is exported by the AmtB facilitator. So here we have presumably resolved the problem of accumulation of the ammonium ion. Desulfonation by Xsc is presumably followed by energy conservation involving dissimilatory sulfite reductase (see Chap. 2 by Fritz et al. and Chap. 3 by Pereira), so there is nothing unusual about a sulfate reducer letting $\mathrm{HS}^{-}\left(\mathrm{H}_{2} \mathrm{~S}\right.$ ?) diffuse out of the cell. The cell has a secondary source of ATP, via acetate kinase, which will lead to the disposal of acetate; again, this is nothing unusual in an anaerobe.

Another of our isolates, Desulfonispora thiosulfatigenes, excretes thiosulfate in place of sulfide (Denger et al. 1999). Yet another isolate, Desulfovibrio sp. strain GRZCYSA, generates sulfate and sulfide (Laue et al. 1997). Disposal of these oxyanions is more difficult to explain, but we have no further data on these processes in anaerobes, so let us consider the corresponding process in aerobes.

The DOE Joint Genomic Institute has recently reannotated the genome sequence of Burkholderia xenovorans LB400 and incorporated our suggestions about taurine metabolism (Brüggemann et al. 2004; Rein et al. 2005; Ruff et al. 2003), while V. Sauvé and B. Berks (personal communication) and C. Dahl (personal communication; see Chap. 9 by Grimm et al.) recommended locating cytochrome $c$ in the periplasm or the cytoplasmic membrane. This allows the development of the following scheme (Fig. 14.7). The inducible pathway presumably consists of, in the carbon-relevant aspect, an ATP binding cassette transporter, a cytochrome $c$ coupled, membrane-bound taurine dehydrogenase (TauXY), the desulfonation by Xsc, phosphate acetyltransferase (phosphotransacetylase; Pta) and further metabolism of acetylcoenzyme A. The inorganic aspects involve ammonia and sulfite. We presume that the AmtB facilitator is present to 


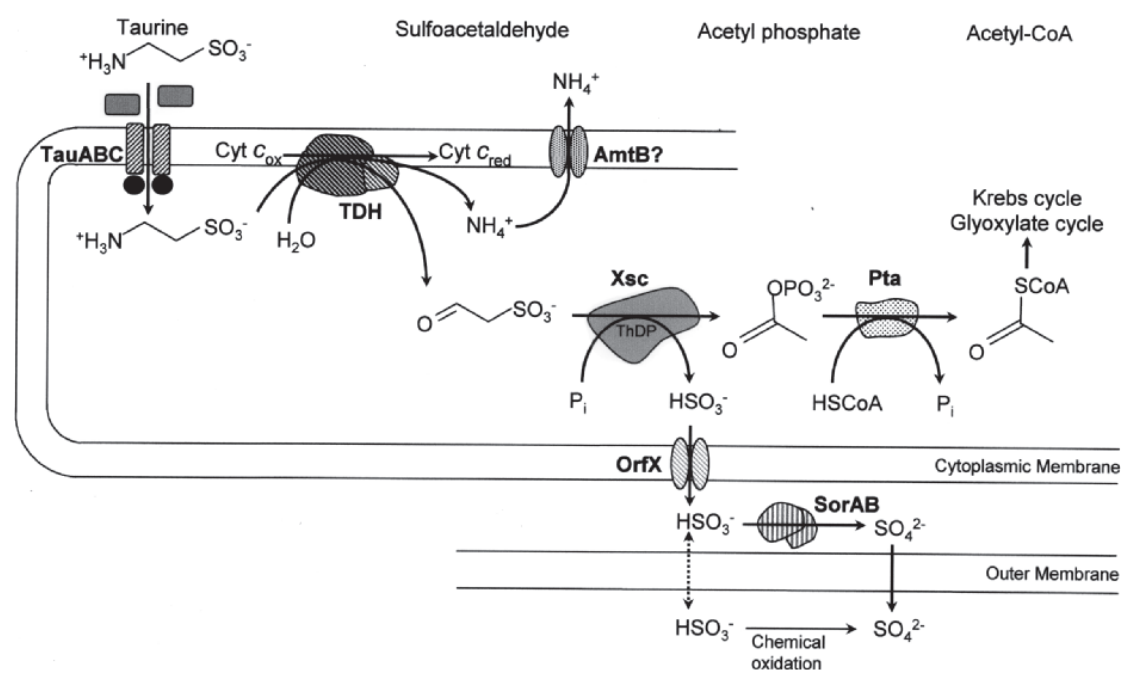

Fig. 14.7 Degradative pathway for taurine in Burkholderia xenovorans LB400. The genome sequence, experimental data on taurine dehydrogenase (TDH), Xsc and Pta (Ruff et al. 2003), with support for sulfite dehydrogenase (SorAB) from a different strain (Table 14.1), and other data (Denger et al. 2006a; Gorzynska et al. 2006; Rein et al. 2005) form the basis for this figure

excrete ammonia. We assume that there is at least one sulfite dehydrogenase present, SorAB (see later), and the organism presumably uses the gene product of $\operatorname{orf} X$, in the xsc-pta-orfX cluster (Brüggemann et al. 2004), to excrete sulfite to the periplasm, where most of the oxyanion is oxidized immediately. Some transient sulfite is detected outside the cell (Table 14.1), which presumably indicates a faster excretion of sulfite via OrfX than oxidation via SorAB.

The overall picture is thus quite complex. There is the desulfonative pathway itself, including the sulfite exporter, but apparently with an independent cytochrome $c$ for taurine dehydrogenase, an independent AmtB and an independent sulfite dehydrogenase. The glyoxylate pathway is also needed. So our intelligent microbes have a sophisticated strategy to deal with the complexities of metabolizing this apparently simple molecule, taurine.

There is considerable biodiversity in this small pathway (Figs. 14.6, 14.7). The diversity continues in the unresolved details of the sulfite dehydrogenases.

\subsection{Sulfite Dehydrogenases in Sulfonate Metabolism}

Lectures at this conference dealt with three major sulfite dehydrogenases, periplasmic SorAB (see Chap. 13 by Kappler), an aspect of the periplasmic Sox system (see Chap. 12 by Friedrich et al.; V. Sauvé and B. Berks, personal communication) and the intracellular, indirect pathway via adenosyl phosphosulfate (see Chap. 2 by 


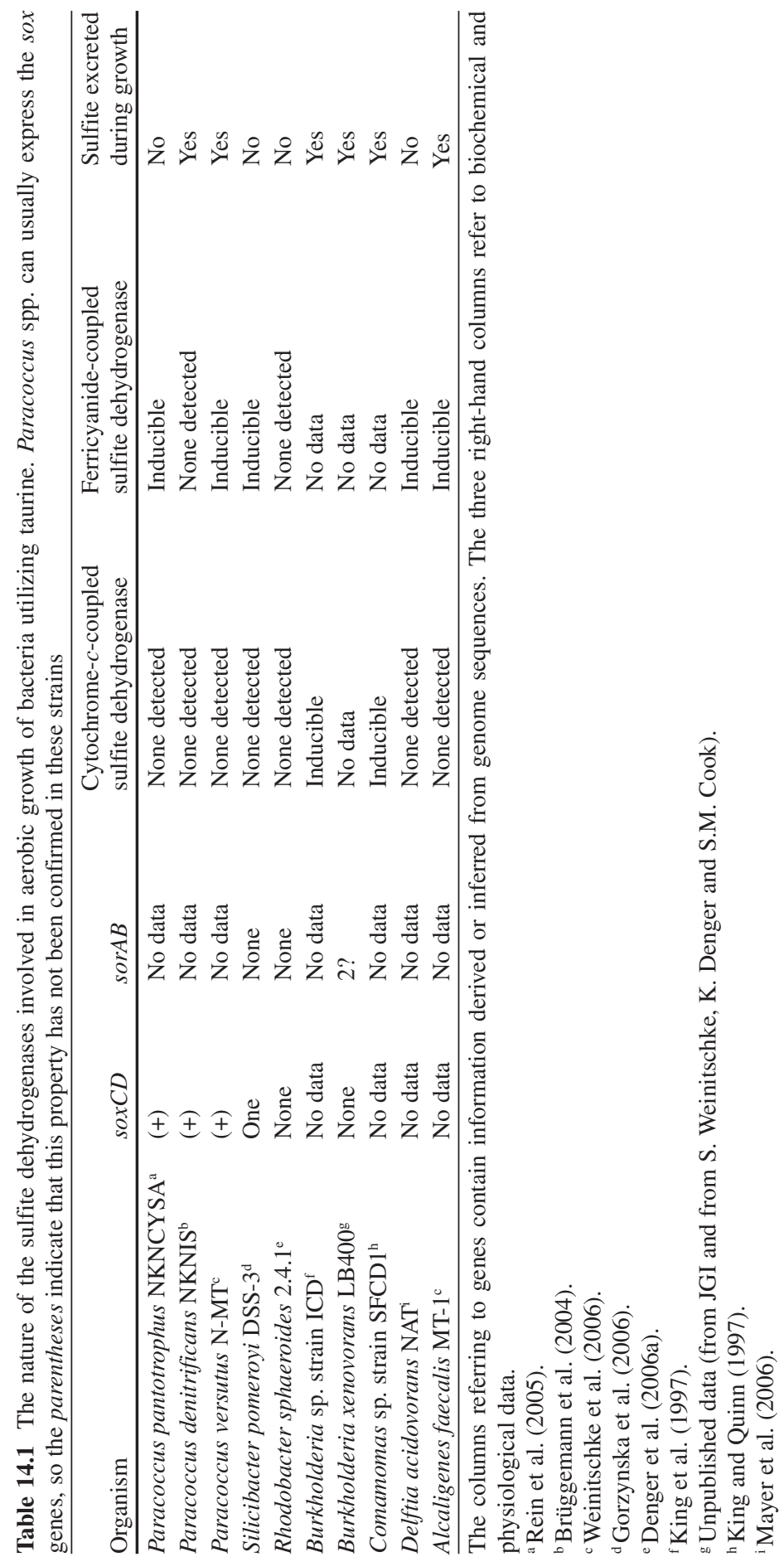


Fritz et al. and Chap. 3 by Pereira) in anoxygenic phototrophs. We have not found the indirect pathway in aerobes (Denger et al. 2006a), which is unsurprising, given the sensitivity of the enzymes to oxygen (see Chap. 2 by Fritz et al.). We suspect that the Sox system is seldom involved, because no organism with the genes on its genome seems to express a cytochrome $c$ coupled sulfite dehydrogenase (Table 14.1). We suspect that SorAB is sometimes involved (Fig. 14.7), because Quinn's group found cytochrome $c$ coupled sulfite dehydrogenase in their Burkholderia sp. strain ICD (King et al. 1997; Ruff et al. 2003), which could correspond with the presence of candidate $\operatorname{sor} A B$ genes in B. xenovorans LB400 (Table 14.1). Quinn's group (King and Quinn 1997) also found candidate SorAB in Comamonas sp. strain SFCD1.

However, the option to oxidize sulfite in the periplasm seems to be only one possibility, and some organisms use different options with different substrates. Silicibacter pomeroyi DSS-3 utilizes taurine, induces a sulfite dehydrogenase and excretes sulfate via an unknown exporter; no sulfite is observed. However, when the organism utilizes L-cysteate with induction of sulfite dehydrogenase, it excretes sulfite almost quantitatively, apparently via CuyZ, a paralogue of TauZ, the presumed sulfate exporter in many Alphaproteobacteria (Denger et al. 2006a, b; Gorzynska et al. 2006; Rein et al. 2005). This sulfite dehydrogenase is arguably cytoplasmic, because a periplasmic enzyme would not allow sulfite to accumulate to significant amounts extracellularly.

We suspect that this sulfite dehydrogenase in S. pomeroyi DSS-3 represents a major group of unknown sulfite dehydrogenases, which is found in many of our isolates (Table 14.1). The enzyme was discovered by Reichenbecher et al. (1999) in a strain of Delftia acidovorans, and only in D. acidovorans have we been able to elute active enzyme from a chromatography column (K. Denger, unpublished data). We hope to be able to characterize this enzyme in the near future.

Some organisms have no detectable sulfite dehydrogenase (Table 14.1), one of which (Paracoccus denitrificans NKNIS) leaks some sulfite during sulfate formation and one of which (Rhodobacter sphaeroides 2.4.1) does not. We are, thus, uncertain whether yet more sulfite dehydrogenases await discovery, or whether the assay conditions used were unsuitable.

\subsection{Conclusions}

Organosulfonates are widespread in Nature. Large amounts of sulfite are used to generate these compounds. Some sulfonates are generated via enzymic or atmospheric oxygenation of sulfhydryl groups.

These organosulfonates are sometimes functional as synthesized, but larger compounds (e.g. lipids, surfactants and even nucleic acids) are also generated.

All these natural compounds are subject to biodegradation in food webs, and there are indications that not only bacteria, but also archaea and protists can cleave 
the stable carbon-sulfonate bond. There is a broad range of enzymes involved in desulfonation and desulfonative pathways.

The product of desulfonation is always sulfite. This sulfite has many possible fates, depending on the type of metabolism in the host organism. Similar degradative pathways are found in strict anaerobes, facultative anaerobes (where they function under both oxic and anoxic conditions) and strict aerobes. Under aerobic conditions, the diversity of sulfite dehydrogenases is incompletely understood.

Cells have developed fairly complex sets of responses to the multiplicity of charged compounds generated during the degradation of these charged organosulfonates. We think that we can describe these phenomena, but our understanding at the molecular level is still very limited.

Acknowledgements. We are grateful to R. Rabus for growing D. psychrophila and to the DOE Joint Genomic Institute for making sequence data available on their Web site, especially for B. xenovorans LB400 and $R$. sphaeroides 2.4.1. Many undergraduate students in our advanced teaching laboratory also contributed to the data. The research in our laboratory was funded by the University of Constance, the DFG, the European Union (SUITE), ECOSOL and CLER, and the LBS Stiftung Umwelt und Wohnen.

\section{References}

Abraham W-R, Strömpl C, Vancanneyt M, Bennasar A, Swings J, Lünsdorf H, Smit J, Moore ERB (2004) Woodsholea maritima gen. nov., sp. nov., a marine bacterium with a low diversity of polar lipids. Int J Syst Evol Microbiol 54:1227-1234

Baker SC, Kelly DP, Murrell JC (1991) Microbial degradation of methanesulphonic acid: a missing link in the biogeochemical sulphur cycle. Nature 350:627-628

Brüggemann C, Denger K, Cook AM, Ruff J (2004) Enzymes and genes of taurine and isethionate dissimilation in Paracoccus denitrificans. Microbiology 150:805-816

Budzikiewicz H, Fuchs R, Taraz K, Marek-Kozaczuk M, Skorupska A (1998) Dihydropyoverdin7-sulfonic acids - unusual bacterial metabolites. Nat Prod Lett 12:125-130

Coleman NV, Spain JC (2003) Distribution of the coenzyme M pathway of epoxide metabolism among ethene- and vinyl chloride-degrading Mycobacterium strains. Appl Environ Microbiol 69:6041-6046

Cook AM, Denger K (2002) Dissimilation of the $\mathrm{C}_{2}$ sulfonates. Arch Microbiol 179:1-6

Cook AM, Denger K (2006) Metabolism of taurine in microorganisms: a primer in molecular diversity? Adv Exp Med Biol 583:3-13

Cook AM, Laue H, Junker F (1999) Microbial desulfonation. FEMS Microbiol Rev 22:399-419

Cook AM, Denger K, Smits THM (2006) Dissimilation of $\mathrm{C}_{3}$-sulfonates. Arch Microbiol 185:83-90

Demarçay H (1838) Ueber die Natur der Galle. Ann Pharm 27:270-291

den Dooren de Jong LE (1926) Bijdrage tot de kennis van het mineralisatieproces. Nijgh \& van Ditmar, Rotterdam

Denger K, Stackebrandt E, Cook AM (1999) Desulfonispora thiosulfatigenes gen. nov., sp. nov., a widespread, taurine-fermenting, thiosulfate-producing, anaerobic bacterium. Int J Syst Bacteriol 49:1599-1603 
Denger K, Smits THM, Cook AM (2006a) Genome-enabled analysis of the utilization of taurine as sole source of carbon or nitrogen by Rhodobacter sphaeroides 2.4.1. Microbiology 152:3197-3206

Denger K, Smits THM, Cook AM (2006b) L-Cysteate sulfo-lyase, a widespread, pyridoxal $5^{\prime}$-phosphate-coupled desulfonative enzyme purified from Silicibacter pomeroyi DSS-3 ${ }^{\mathrm{T}}$. Biochem J 394:657-664

Dominy JE Jr, Simmons CR, Karplus PA, Gehring AM, Stipanuk MH (2006) Identification and characterization of bacterial cysteine dioxygenases: a new route of cysteine degradation in eubacteria. J Bacteriol 188:5561-5569

Feigel BJ, Knackmuss H-J (1993) Syntrophic interactions during degradation of 4-aminobenzenesulfonic acid by a two species bacterial culture. Arch Microbiol 159:124-130

Gorzynska AK, Denger K, Cook AM, Smits THM (2006) Inducible transcription of genes involved in taurine uptake and dissimilation by Silicibacter pomeroyi DSS- $3^{\mathrm{T}}$. Arch Microbiol 185:402-406

Graham DE, Xu H, White RH (2002) Identification of coenzyme M biosynthetic phosphosulfolactate synthase: a new family of sulfonate biosynthesizing enzymes. J Biol Chem 277:13421-13429

Hickford SJH, Küpper FC, Zhang G, Carrano CJ, Blunt JW, Butler A (2004) Petrobactin sulfonate, a new siderophore produced by the marine bacterium Marinobacter hydrocarbonoclasticus. J Nat Prod 2004:1897-1899

Huxtable RJ (1992) Physiological actions of taurine. Physiol Rev 72:101-163

Jacobson JG, Smith LH (1968) Biochemistry and physiology of taurine and taurine derivatives. Physiol Rev 48:424-511

Johnston JB, Murray K, Cain RB (1975) Microbial metabolism of aryl sulphonates. A reassessment of colorimetric methods for the determination of sulphite and their use in measuring desulphonation of aryl and alkylbenzene sulphonates. Antonie Van Leeuwenhoek 41:493-511

Junker F, Field JA, Bangerter F, Ramsteiner K, Kohler H-P, Joannou CL, Mason JR, Leisinger T, Cook AM (1994a) Oxygenation and spontaneous deamination of 2-aminobenzenesulphonic acid in Alcaligenes sp. strain O-1 with subsequent meta ring cleavage and spontaneous desulphonation to 2-hydroxymuconic acid. Biochem J 300:429-436

Junker F, Leisinger T, Cook AM (1994b) 3-Sulphocatechol 2,3-dioxygenase and other dioxygenases (EC 1.13.11.2 and EC 1.14.12.-) in the degradative pathways of 2-aminobenzenesulphonic, benzenesulphonic and 4-toluenesulphonic acids in Alcaligenes sp. strain O-1. Microbiology 140:1713-1722

Kelly DP, Murrell JC (1999) Microbial metabolism of methanesulfonic acid. Arch Microbiol 172:341-348

King JE, Jaouhari R, Quinn JP (1997) The role of sulfoacetaldehyde sulfo-lyase in the mineralization of isethionate by an environmental Acinetobacter isolate. Microbiology 143:2339-2343

King JE, Quinn JP (1997) Metabolism of sulfoacetate by environmental Aureobacterium sp. and Comamonas acidovorans isolates. Microbiology 143:3907-3912

Knepper TP, Berna JL (2003) Surfactants: properties, production, and environmental aspects. In: Knepper TP, Barceló D, de Voogt P (eds) Analysis and fate of surfactants in the aquatic environment. Elsevier, Amsterdam, pp 1-50

Kondo H, Ishimoto M (1972) Enzymatic formation of sulfite and acetate from sulfoacetaldehyde, a degradation product of taurine. J Biochem 72:487-489

Laue H, Denger K, Cook AM (1997) Fermentation of cysteate by a sulfate-reducing bacterium. Arch Microbiol 168:210-214

Lie TL, Leadbetter JR, Leadbetter ER (1998) Metabolism of sulfonic acids and other organosulfur compounds by sulfate-reducing bacteria. Geomicrobiol J 15:135-149

Mayer J, Denger K, Smits THM, Hollemeyer K, Groth U, Cook AM (2006) N-Acetyltaurine dissimilated via taurine by Delftia acidovorans NAT. Arch Microbiol 186:61-67

O'Neil MJ (2001) International nonproprietary names (INN) for radicals and groups proposed for pharmaceutical substances by the World Health Organization. In: The Merck index. Merck, Whitehorse Station

Ovenden SPB, Capon RJ (1999) Echinosulfonic acids A-C and echinosulfone A: novel bromoindole sulfonic acids and a sulfone from a southern Australian marine sponge, Echinodictyum. J Nat Prod 62:1246-1249 
Rabus R, Ruepp A, Frickey T, Rattei T, Fartmann B, Stark M, Bauer M, Zibat A, Lombardot T, Becker I, Amann J, Gellner K, Teeling H, Leuschner WD, Glöckner F-O, Lupas AN, Amann R, Klenk H-P (2004) The genome of Desulfotalea psychrophila, a sulfate-reducing bacterium from permanently cold Arctic sediments. Environ Microbiol 6:887-902

Reichenbecher W, Kelly DP, Murrell JC (1999) Desulfonation of propanesulfonic acid by Comamonas acidovorans strain P53: evidence for an alkanesulfonate sulfonatase and an atypical sulfite dehydrogenase. Arch Microbiol 172:387-392

Rein U, Gueta R, Denger K, Ruff J, Hollemeyer K, Cook AM (2005) Dissimilation of cysteate via 3-sulfolactate sulfo-lyase and a sulfate exporter in Paracoccus pantotrophus NKNCYSA. Microbiology 151:737-747

Ruff J, Denger K, Cook AM (2003) Sulphoacetaldehyde acetyltransferase yields acetyl phosphate: purification from Alcaligenes defragrans and gene clusters in taurine degradation. Biochem J 369:275-285

Sanda S, Leustek T, Theisen MJ, Garavito RM, Benning C (2001) Recombinant Arabidopsis SQD1 converts UDP-glucose and sulfite to the sulfolipid head group precursor UDPsulfoquinovose in vitro. J Biol Chem 276:3941-3946.

Schleheck D, Knepper TP, Fischer K, Cook AM (2004) Mineralization of individual congeners of linear alkylbenzenesulfonate (LAS) by defined pairs of heterotrophic bacteria. Appl Environ Microbiol 70:4053-4063

Stipanuk MH (2004) Sulfur amino acid metabolism: pathways for production and removal of homocysteine and cysteine. Annu Rev Nutr 24:539-577

Suzuki T, Wada T, Saigo K, Watanabe K (2002) Taurine as a constituent of mitochondrial tRNAs: new insights into the functions of taurine and human mitochondrial diseases. EMBO J 21:6581-6589

Tiedemann F, Gmelin L (1827) Einige neue Bestandtheile der Galle des Ochsen. Ann Phys Chem 9:326-337

Vairavamurthy A, Zhou W, Eglinton T, Manowitz B (1994) Sulfonates: a new class of organic sulfur compounds in marine sediments. Geochim Cosmochim Acta 58:4681-4687

Vollrath F, Fairbrother WJ, Williams RJP, Tillinghast EK, Bernstein DT, Gallagher KS, Townley MA (1990) Compounds in the droplets of the orb spider's viscid spiral. Nature 345:526-528

Weinitschke S, Denger K, Smits TMH, Hollemeyer K, Cook AM (2006) The sulfonated osmolyte $\mathrm{N}$-methyltaurine is dissimilated by Alcaligenes faecalis and by Paracoccus versutus with release of methylamine. Microbiology 152:1179-1186

Weinstein CL, Griffith OW (1988) Cysteinesulfonate and $\beta$-sulfopyruvate metabolism. Partitioning between decarboxylation, transamination, and reduction pathways. $\mathrm{J}$ Biol Chem 263:3735-3743

White RH (1984) Biosynthesis of the sulfonolipid 2-amino-3-hydroxy-15-methylhexadecane1-sulfonic acid in the gliding bacterium Cytophaga johnsonae. J Bacteriol 159:42-46

White RH (1986) Intermediates in the biosynthesis of coenzyme M (2-mercaptoethanesulfonic acid). Biochemistry 25:5304-5308

Yancey PH, Blake WR, Conley J (2002) Unusual organic osmolytes in deep-sea animals: adaptations to hydrostatic pressure and other perturbants. Comp Biochem Physiol A Mol Integr Physiol 133:667-676 